\title{
Problems and Suggestions of Rural Information Service Platform Construction in China
}

\author{
Lili Guan, Hongliang Zhao*, Ping Xu, Liyong Xie and Wen Zhang \\ College of Agronomy, Shenyang Agriculrtural University, Dongling Road No.120, Shenhe District, Shenyang City, Liaoning \\ Province, China \\ ${ }^{*}$ Corresponding author
}

\begin{abstract}
China's agricultural information service work cannot fully meet the needs of farmers, and need to explore more effective information services. This paper reviews the construction achievements and research achievements of China's agricultural information service platform by literature analysis, and obtains the information demand of farmers according to the social survey. The results show that farmers gradually accept the agricultural information service platform, and began to use mobile terminals to obtain agricultural information. The paper puts forward the solution of China's agricultural information service platform, and points out that the main trend of future agricultural information service is based on mobile information service.
\end{abstract}

Keywords-component; rural information service platform; current situation; problem; suggestion

\section{INTRODUCTION}

Since the third Plenary Session of the 11th CPC Central Committee in 1978, China has begun the great practice of reform and opening to the outside world ${ }^{[1-3]}$. Great changes have taken place in every field of our country, and agriculture is no exception. Agricultural production has increased and farmers' income has been fruitful. Since the new century, with the continuous development and change of social economy, farmers are no longer satisfied with the meager benefits of traditional agriculture, but the demand for new varieties, new technologies and market dynamics is becoming more and more urgent. With the rapid development of media, network and communication industry, agricultural informatization has emerged in china. As an important component of agricultural informatization construction, rural information service platform has not only been paid attention to, but also made some achievements in recent years.

The rural information service includes many contents. In different countries, it plays different roles. In developed countries, most of field was healthcare for famers ${ }^{[4-8]}$, while agricultural science and technology in developing countries ${ }^{[9-}$ 12].

This paper starts with the rural informatization platform in our country, analyzes its current situation and problems, and finally puts forward some suggestions and countermeasures. It will provide theoretical basis and practical reference for the construction of rural information service platform in china.

\section{THE POLICY BACKGROUND OF RURAL INFORMATIZATION IN CHINA}

From the sixteen people's Congress of using information to promote industrialization, it promote the informationization with industrialization, taking a new road to industrialization" to the seventeen people's Congress of "informationization, industrialization, urbanization, marketization and internationalization" five strategic tasks, and then to the eighteen session of the National People's Congress of the four coordinated development. From 2005 to 2017, the No.1 document of the Central Committee of the Communist Party of China referred to the construction of agricultural information continuously, and the level of attention increased year by year. In 2017, the No.1 document of the CCCPC dealt with many aspects of agricultural informatization in rural areas, and at the same time emphasized the promotion of agricultural e-commerce. Therefore, it has become an urgent need to implement the Scientific Outlook on Development, build a harmonious society, build an innovative country, solve the bottleneck problem of economic and social development, and guarantee the long-term stability of the state.

\section{THE DEVELOPMENT OF RURAL INFORMATION SERVICE PLATFORM IN CHINA}

China's rural informatization started relatively late. The prototype is the rural statistical work under the planned economy. It can be said to be congenitally deficient, but under the strong advocacy of the state, under the efforts of personnel at all levels, China's agricultural informatization has developed rapidly, and has also made many gratifying achievements. For example, the "intelligent rural information technology application demonstration project" implemented by the state "863" plan has established 20 demonstration areas throughout the country. The project of National Key Technologies R \& D Program of China about rural expert decision making system and information technology system has been implemented .The system has been developed 5 rural expert system development platforms with independent intellectual property rights, 12 information resource databases, 35 popularization and application computer networks, and more than 200 practical rural expert systems,and it laid a solid foundation for the implementation of rural informatization strategy, and accumulated valuable experience. 
The construction of agricultural information service platform in China can be divided into the following types. On the one hand, the government led construction of national and provincial information platform, such as China Agricultural Information Network. On the other hand, relying on agricultural research institutions to carry out the platform construction, such as the construction of new rural information service platform of Shenyang Agricultural Uinversity, platform construction is comprehensive and systematic, involving all aspects of agriculture. From the point of view of the technology used,some based on traditional Internet about NET technologies and some based on the design of mobile technology service platform.

\section{The Problems Existing In the Construction of RURAL INFORMATION SERVICE PLATFORM IN CHINA}

Of course, when we achieve certain achievements, there are still many problems in the process of rural informatization construction. The following problems are discussed in the course of the construction of rural information service platform.

\section{A. Lack of Human Resources}

At the upsurge of research and practice of rural informatization, people from all parts of the country have explored and studied them from their own point of view, but they lack authoritative arguments and lack systematic study. , and there are too many generally speaking discussions and few specific questions, which makes the study of rural informatization itself lack of depth and breadth. Of course, it will influence and limit the construction of rural informatization. It lack of strong strategic forward-looking leader. "Pioneer" refers to the specialized personnel of agricultural informatization, and the designers of rural information service platform. If we are to be qualified for the position of comprehensive knowledge, we should not only know the network technology, but also know the agricultural expertise. We should understand the policy of agricultural informatization and the market trend. However, this kind of talent is still scarce in our country.As far as the "vanguard" is concerned; there are always many technical barriers. Like agricultural experts do not understand network technology, it is difficult to finance professional knowledge and network, network experts often do not understand the agriculture, and between agricultural experts and network experts often lack of academic exchanges and communication, is a direct result of their design of agricultural service website is not professional and not applicable.

"Main force" refers to the staff at the grass-roots level, that is, the platform maintainer and manager. However,this part of people often appear problems are: insufficient understanding, information consciousness is not strong; surface work is much; professional is not strong; work enthusiasm is not strong.

\section{B. Low Platform Utilization and Poor Effectiveness}

Although the country has launched a series of initiatives, such as "computer to the countryside" and "millions of farmers' access to the Internet", the Internet access rate of farmers is still low. The reasons for this situation are many.
From the farmers' perspective, first, using the concept of farmers' online information has not been established; the vast majority of farmers are still in a traditional way such as TV and radio as the main channel of access to information. But in developed countries, many farmers use network information to guide agricultural production and management; Second, the farmer's income level is lower, but the network computer cost is higher; Third, farmers are more conservative in their thinking. It is understood that in China's vast numbers of farmers, illiteracy and semi illiteracy accounted for more than $20 \%{ }^{[5]}$, we can see that the cultural quality of farmers is low, and the ability to accept knowledge is poor. Moreover, from the platform point of view, the platform design is unreasonable, the information update is slow, the quality of the platform is low, the farmer login platform but cannot find the desired information, and the actual effect is poor.

\section{Shortage Of systematic Design}

Because of the particularity of the development of China's agricultural informationization background, short-term development, all levels of various industries have even started to build their own agricultural information service platform, platform construction process lack of coordination, often think of the various government, caused by the difference of system platform construction. These platforms are not perfect from the database, plate design, information updating, etc., and each has its own classification system and standards, lack of information and interaction between each other, and it is difficult to share information.Not only waste of information platform construction resources, but also affect the normal operation of the platform.

\section{Lack of Specialty}

Nowadays, various departments at all levels have launched a large number of rural information service websites and platforms, while the levels of website platform to become bigger and full as the goal, mostly released are general and common sense of information, often repeated construction and waste of resources, the author looked to "full" "big" the goal of building itself is not wrong, but the actual situation is still a big gap between the expectations and the common. At the national level, the platform can be targeted at all levels and large, and the provincial and local information platforms can be built into a professional and characteristic platform, which is more suited to the needs of local farmers.

\section{E. Lack of Long-term Management Mechanism}

In the past few years, under the guidance of the national policy, the rural information service platform has been springing up all over the country, and people feel that the construction of China's rural informatization will develop by leaps and bounds. Indeed, the level of China's rural informatization has been greatly improved, but we need to be honest and rational to look at this problem. For example, although the construction of the platform site, but how many of them are effective website, how many people to pay attention to them and their practical application; whether the website platform information update; whether the site management in place, whether there is halfway situation, 
whether there is a long-term management mechanism. These problems more or less exist.

\section{F. Uneven Development, Large Regional Differences}

As the level of economic development in different regions of our country is quite different, it leads to uneven development of agricultural informatization and regional differences, which brings inconvenience to the unified construction and management of agricultural informatization in china. This phenomenon is more prominent in the provincial platform, the province development is not balanced, which provide information difficulties, and the difference of information needs of rural residents in different regions is obvious, so it is difficult to provide a unified information content.

\section{SugGeStions ON THE CONSTRUCTION OF RURAL INFORMATION SERVICE PLATFORM IN CHINA}

\section{A. Establish and Improve the Platform from the State to the Local Level, and Achieve Coordination}

The state and government led in-depth implementation of the "golden agriculture project" construction, which focus on four levels of agricultural information service platform from state to county. The main purpose is to establish unified standards and overall planning and construct of overall information service platform system. And all levels of the platform at all levels of integration, forming subsystems. To promote the relationship between the total system and subsystems, subsystems, and then build the largest platform and agricultural information service database.

\section{B. Strengthen The Professional And Characteristic Construction Of Regional Service Platform}

Information service is an organic whole, is a great undertaking for a long time, and this is not the individual sector that can be reached. It is better to put this goal on the whole as a whole, rather than the individual department. Make a good self-orientation and show its own characteristics. For example, based on the research institutes and colleges and universities as the basis for the construction of the platform, it should highlight its cutting-edge research trends and academic characteristics. Enterprises should pay more attention to the role of the market and the benefits of the products. But the national level, the provincial level, should serve as "the manager", will integrate the characteristic website of each department at all levels to own banner, and completes the link and the summary.

Combined with local agricultural production and rural realities, we will focus on strengthening the professionalism and characteristic construction of regional platforms. Highlight local characteristics, strengthen professional and technical capacity, change the service mode of the past and large, and strengthen the ability and level of serving local characteristic industries.

\section{The Importance and Role of Universities and Scientific Research Institutes in Agricultural Informatization Construction.}

The most common construction of China's rural information service platform is the government led policy platform or enterprise led for-profit platform. However, in the forefront of science and technology, agriculture, universities and research institutes specializing in agricultural technology are often overlooked in this regard. It is known that China's agricultural colleges and universities as the basis for the construction of rural service platform is still a small minority. The primary point of the construction of rural service platform is the access and collection of information resources, and agricultural universities and research institutes are the important sources of these information. Without these sources of information, the rural information service platform will grow like trees without soil. The platform construction and the communication of these units are not deep enough, and they cannot give full play to their functions and effectiveness. Some changes should be made to make the information more authoritative, forward and continuous, better serve the rural areas and serve the farmers, and meet the needs of the development of the market economy.

\section{Establish A Long-term Management Mechanism, Improve Agricultural Information Collection, Distribution And Management System}

Only by establishing a long-term management mechanism, improving the system of agricultural information collection and distribution and management, the long-term development and survival can be achieved. In view of the current situation of rural service platform management in China, the author advocates the idea of overall coverage, class management and regional governance. Specifically, the overall coverage refers to the power and position, stressed that national informatization construction departments to establish a longterm management system generally pay attention to important points, at the national level; Class management refers to the area to establish the specific direction of local management system, reward and punishment, establish performance appraisal system, give appropriate praise to regional level units outstanding, instead give appropriate criticism and punishment; Regional governance means giving full autonomy to the place. You can establish a suitable local information collection and management system in the national publication system make it more operational and practical, but also to mobilize local enthusiasm in rural informatization construction. We will improve the collection, distribution and management system of agricultural information, in order to enter the information more standard, higher quality, more timely.

\section{E. Strengthen the Comprehensive Training of Talents in Agricultural Informatization and Highlight the Role of Talent}

Talent construction is a necessary prerequisite for information construction. Strengthen the comprehensive training of agricultural information talents, highlight the role of talent, beneficial for overcoming technical problems exist for a long time, beneficial for the overall development of 
information platform, beneficial for improving individual ability and the quality of rural informatization talents. And reserve a large number of human resources for the sustainable construction and development of rural informatization.

\section{F. Strengthen Rural Information Education. Importance and} Necessity of Propaganda and Construction of Agricultural Information Service Platform.

First, it is to strengthen the education and training of farmers. As the rural information platform, in preparation for the premise of the premise, we should conduct extensive publicity, increase social awareness, so that farmers know the existence of the platform. Publicity process should pay attention to the comprehensive application of various media, both for the mass media for farmers, such as radio and television, but also directly facing the rural propaganda and publicity columns. In addition, we should fully mobilize the resources and advantages of all sides. It let farmers understand the platform, understand the platform, use the platform, participate in the platform. Second, strengthen the education of platform builders. Rural informatization is an organic whole, and it is a great undertaking for a long time. Too much emphasis on the importance of the individual will split the overall, forming a platform between the feelings, reduce financing platform interaction between. Not conducive to the development of the whole, but it will affect the development of the whole. Therefore, researchers should stand at a certain height, do not seek immediate benefits.

Third, to strengthen public education, let everyone realize the importance of rural informatization, actively participate in the construction of rural informatization, and can promote the development of rural informatization in the whole industry, forming a good situation of national participation and atmosphere, provide a good external environment for the development of rural informatization.

\section{CONCLUSION}

The construction of rural information service platform is an organic whole, and it is a great undertaking for a long time. For the region, should pay more attention to how to place is more suitable to provide more professional service, how to make the long-term healthy development, how to improve the overall level of the whole area of rural informatization. To coordinate the relationship between the immediate interests and long-term interests, coordinate the relationship between the rural informationization and social informationization, further coordination of city development and rural development is deeply discussed should be all units at all levels of the problem. In general, the momentum of rural informatization construction in our country has made gratifying achievements, but we cannot satisfy and immersed in the results, to actively carry out reflection and summary, looking for experience in success, to seek lessons in the problem, efforts to explore a line with the Chinese conditions with the vitality of long-term development the road.

\section{ACKNOWLEDGMENT}

The research is funded by the innovation and entrepreneurship training program of Liaoning university students in China (201510157071,20510157007).

\section{REFERENCES}

[1] Newman L,Bidargaddi N,Schrader G. Service Providers' Experiences of Using a Telehealth Network 12 Months After Digitisation of a Large Australian Rural Mental Health Service[J]. International Journal of Medical Informatics, 2016, 94: 8-20.

[2] Xiang, J. H., Xiao, L., Meng, X. F., Cui, L., Xiao, N., \& Jin, C. Z.. The situation and evaluation of china agriculture information website development. Agriculture Network Information. 2006

[3] Verbeke W. Agriculture and the food industry in the information age[J] European Review of Agricultural Economics, 2005, 32(3):347-368.

[4] Zahedi S M, Zahedi S R. Role of Information and Communication Technologies in Modern Agriculture[J]. Physical Review Letters, 2012, 92(13):475-487

[5] Wolfert J. Developments on Precision Agriculture and Information Management in The Netherlands and Europe[J]. Canadian Journal of Chemistry, 2011, 56(2):218-220.

[6] Kawai K. Hi-technology and development strategy in regional agriculture, 22: Agricultural information system and its prospects (1).[J]. Journal of Agricultural Science, 1988

[7] Mäkinen H, Rimhanen K, Kaseva J, et al. Information needs, barriers and incentives to adopting climate change mitigation and adaptation actions in boreal agriculture[J]. Climate Research, 2017, 72(3):165-176.

[8] Prokopy L S, Carlton J S, Arbuckle J G, et al. Extension' s role in disseminating information about climate change to agricultural stakeholders in the United States[J]. Climatic Change, 2015, 130(2):261272

[9] Wang Yubin, Bo Jingyi, Liu Xiyin. Design of Agricultural Information Service Platform Based on Mobile Technology [J]. Agricultural Science and Technology, 2016, (23): $84+89$. (in Chinese with English abstract)

[10] Kong Fantao, Chen Ping, Wang Ping, Liu Han, Li Huishang, Zhang Jianhua.China's agricultural information construction practice and thinking - based on "Liaoning model" exploration and enlightenment [J]. Agricultural modernization research, 2016, (03 ): 416-422. (in Chinese with English abstract)

[11] Research on the Construction of Agricultural Information Service System in "Four Modernizations" [J]. Agricultural Economics and Management, 2015, (06): 46- 52. (in Chinese with English abstract)

[12] Zhou Jiannong, Yang Yuanyuan, Ren Ni.Study on utilization rate and satisfaction degree of agricultural information service platform - Taking Jiangsu Province as an example [J]. Journal of Library and Information Sciences in Agriculture, 2015, (03): 8-12. (in Chinese with English abstract) 